\title{
Authors' reply: Rabid puppy-dog imported into the Netherlands from Morocco via Spain, February 2012
}

G G van Rijckevorsel (gvrijckevorsel@ggd.amsterdam.nl) ${ }^{1}$

1. Public Health Service Amsterdam, Amsterdam, the Netherlands

Citation style for this article:

an Rijckevorsel GG. Authors' reply: Rabid puppy-dog imported into the Netherlands from Morocco via Spain, February 2012.

Euro Surveill. 2012;17(12):pii=20125. Available online: http://www.eurosurveillance.org/ViewArticle.aspx?Articleld=20125

To the editor: The additional information from the Spanish Health Authorities is much appreciated. In their letter the Spanish Health Authorities express their concerns about the informal channels used by the Amsterdam Public Health Service in tracing three persons living in Spain (Contacts 1, 2 and 3). In their opinion access to the personal details of these contacts was denied because of Dutch national laws prohibiting such disclosure of information. However, Dutch national laws do allow Public Health Services to reveal personal data to third parties, but only with the approval of the involved contact, or when contacts cannot otherwise be reached. Also, in case of direct health emergency this law can be overruled.

The Amsterdam Public Health Service regrets the confusion caused in this case by not using the official channels in the process of contact investigation. However, in this case the owners of the rabid dog had contacted their three personal friends before the official channels could be informed. Upon realising these friends were likely at risk (Category II and III exposure), the Amsterdam Public Health Service considered it right at that time to advise them persons to consult a doctor as soon as possible for post-exposure prophylaxis. Rabies is a devastating infectious disease which only can be prevented by timely post-exposure prophylaxis. Identifying contacts is therefore of utmost importance and needs immediate public health action. As described in the rapid communication, the Centre for Infectious Disease Control at the National Institute for Public Health and the Environment (Clb/RIVM) informed their Spanish counterparts at the earliest convenience with as much detailed information as was available at that time.

The lesson learnt from this case is that clear communication between all parties involved is needed for a successful response to public health threats which require instant actions. 